Rev. Bras. Saúde Prod. Anim., Salvador, v.13, n.3, p.682-693 jul./set., 2012 http://www.rbspa.ufba.br ISSN 15199940

\title{
Níveis de células somáticas sobre a proteólise do queijo Mussarela
}

\author{
Somatic cell count on proteolysis in mozzarella cheese
}

\author{
COELHO, Karyne Oliveira ${ }^{1}$; MESQUITA, Albenones José de ${ }^{2}$; MACHADO, Paulo \\ Fernando3; OLIVEIRA, Antonio Nonato de ${ }^{2}$; SOUZA, Cleusely Matias de $\mathrm{de}^{2}$ MEYER, \\ Paula Marques ${ }^{4}$
}

\footnotetext{
${ }^{1}$ Universidade Estadual de Goiás, Unidade de São Luís de Montes Belos, Departamento de Zootecnia e Tecnologia em Laticínios, Goiânia, Goiás, Brasil.

${ }^{2}$ Universidade Federal de Goiás, Escola de Medicina Veterinária e Zootecnia, Departamento de Medicina Veterinária, Goiânia, Goiás, Brasil.

${ }^{3}$ Universidade de São Paulo, Escola Superior de Agricultura "Luiz de Queiroz", Departamento de Zootecnia, Piracicaba, São Paulo, Brasil.

${ }^{4}$ Instituto Brasileiro de Geografia e Estatística, Pirassununga, São Paulo, Brasil.

*Endereço para correspondência: kocoelho@yahoo.com.br
}

\section{RESUMO}

Objetivou-se, com a realização deste trabalho, avaliar o efeito do nível de células somáticas sobre a microbiota e a proteólise do queijo Mussarela, durante o período de armazenamento. Foram selecionadas vacas com contagem de células somáticas $\leq 200 \mathrm{mil}$ células $/ \mathrm{mL}$; de $>200$ a $\leq 400 \mathrm{mil}$ células $/ \mathrm{mL}$; de $>400 \mathrm{mil}$ células $/ \mathrm{mL}$ a $\leq 750 \mathrm{mil}$ células $/ \mathrm{mL}$ e $>750 \mathrm{mil}$ células $/ \mathrm{mL}$ e que não tinham recebido tratamento com antimicrobianos nos dias que antecederam a coleta da matéria-prima. Os queijos produzidos foram avaliados após 1; 15 e 30 dias de armazenamento para a contagem de coliformes a $35^{\circ} \mathrm{C}$, coliformes a $45^{\circ} \mathrm{C}$, psicrotróficos e bactérias ácido lácticas. Paralelamente, foram determinados os índices de extensão e profundidade da proteólise. O experimento completo foi repetido quatro vezes e o delineamento experimental foi em blocos aleatórios. $\mathrm{Na}$ análise estatística, utilizou-se a análise de variância seguida do teste de Tukey, considerando $\mathrm{p}<0,05$ como probabilidade mínima aceitável para diferença entre as médias. O leite com elevada contagem de células somáticas apresentou concentração menor de proteína e maior de nitrogênio não proteico. Observou-se diminuição das bactérias ácido lácticas no queijo elaborado com leite composto de células somáticas $>750$ mil células $/ \mathrm{mL}$. Não obstante, ocorreu um aumento significativo na extensão e profundidade da proteólise durante o período de armazenamento, resultados observados nos queijos fabricados com o leite com células somáticas $>400$ mil células $/ \mathrm{mL}$. Portanto, para se produzir um queijo Mussarela de boa qualidade torna-se necessário o controle da matéria prima, e esta deve apresentar células somáticas inferiores a 400mil células/mL.

Palavras-chave: mastite, qualidade, sub-clínica, vida de prateleira.

\section{SUMMARY}

The aim of this trial was to evaluate the effect of somatic cells count on the microbiota and proteolysis of Mozzarella cheese during the storage period. Cows presenting different levels of SCC were selected: $\leq 200,000$ cells $/ \mathrm{mL}$; $>200,000$ to $\leq 400,000$ cells $/ \mathrm{mL} ;>400,000$ cells $/ \mathrm{mL}$ to $\leq 750,000$ cells $/ \mathrm{mL}$ and $>750,000$ cells $/ \mathrm{mL}$, which were not treated with antimicrobial prior or on the milk sampling day. The cheeses produced were evaluated after 1, 15 and 30 days of storage for coliforms count at $35^{\circ} \mathrm{C}$, coliforms count at $45^{\circ} \mathrm{C}$, psychrotrophic and lactic acid bacteria. Meanwhile, extent and depth of proteolysis indexes were determined. The complete trial was repeated four times and experimental design used was randomized blocks. ANOVA was used for repeated measurements and the p-value was adjusted for multiple comparisons by Tukey's test. High somatic cell count milk showed lower 
concentration of protein and higher of nonprotein nitrogen. There was a decrease of lactic acid bacteria in cheese made from milk containing high somatic cells count $(>750,000$ cells $/ \mathrm{mL})$. Nevertheless, during the storage period, a significant increase in the extent and depth of proteolysis occurred in cheeses produced from milk with SCC higher than 400,000 cells $/ \mathrm{mL}$. Therefore, in order to produce a high quality Mozzarella cheese, it is necessary to control the raw material, so that SCC should be lower than 400,000 cells $/ \mathrm{mL}$.

Keywords: mastitis, quality, shelf-life, subclinical.

\section{INTRODUÇÃO}

A Mussarela é o tipo de queijo de massa filada mais produzido no Brasil. Este é utilizado principalmente no preparo de pizzas e deve apresentar boas propriedades funcionais, especialmente, no que concerne ao fatiamento e derretimento. Entre os fatores que podem influenciar negativamente sobre esses parâmetros, destaca-se a ocorrência de mastite nos rebanhos, a qual compromete a qualidade da matéria prima utilizada no processamento dos queijos (SANTOS et al., 2003ab).

A mastite é uma condição inflamatória complexa da glândula mamária que causa um aumento das células somáticas do leite. A elevada quantidade dessas células resulta em diminuição da vida de prateleira do leite pasteurizado, de modo a afetar negativamente a sua qualidade sensorial (OLIVEIRA et al., 2010). Tais problemas são também relatados em queijos (MAZAL et al., 2007), e isso ocorre pela ação das proteases produzidas pelas células somáticas sobre a caseína (ALBENZIO et al., 2004).

A proteólise endógena do leite ocorre devido à atividade da plasmina e das proteases produzidas pelas células somáticas. Kelly \& Mcsweeney (2002) relataram que as células somáticas defendem o úbere das infecções, a partir da liberação de enzimas proteolíticas ativas, como a plasmina, elastase, colagenase e catepsina. Além dos fatores proteolíticos o aumento da contagem de células somáticas (CCS) cursa com alterações nos fatores antimicrobianos, por meio do aumento destes, o que promove uma injuria da microbiota utilizada nos processos de fermentação industrial, como a do queijo. Isso reflete na dificuldade de acidificação da massa no processo de coagulação (SANTOS e FONSECA, 2007).

A plasmina possui papel central nessa atividade, haja vista poder clivar, rapidamente, a molécula de caseína em polipeptídios menores (PARK, 2001). MAZAL et al. (2007) ilustram tal fato ao descreveram o incremento da atividade proteolítica em queijo tipo prato, produzido com leite composto de CCS alta $>600 \mathrm{mil}$ céls. $/ \mathrm{mL}$. Revilla et al., (2007) relataram a atividade proteolítica de queijos produzidos com leite de ovino elaborado com CCS superior a 2,5 milhões de céls/mL.

Todos esses fatores podem contribuir em maior ou menor grau para a apresentação de alterações significativas na produção e vida de prateleira de queijos. Assim, objetivou-se, com a realização deste trabalho, determinar o efeito do nível de células somáticas sobre as características microbiológicas e a proteólise no queijo Mussarela, durante o período de armazenamento.

\section{MATERIAL E MÉTODOS}

O leite utilizado, no presente experimento, foi obtido na unidade de produção do Departamento de Produção Animal da Escola Veterinária da Universidade Federal de Goiás (DPA/EV/UFG). O plantel era 
constituído de 45 vacas em lactação com produção média de $640 \mathrm{~L} /$ dia.

Foram selecionadas 30 vacas que se encontraram em estágio de lactação superior a 10 dias e que não tinham recebido tratamento com antimicrobianos, nos dias que antecederam a coleta do leite. Para a seleção dos animais, procedeu-se, na ordenha da manhã, a colheita das amostras de leite de cada vaca em lactação, após homogeneização do leite, por no mínimo 10 segundos no balão medidor. Em seguida fez-se a colheita de $40 \mathrm{~mL}$ de leite em frascos que continham uma pastilha conservante Bronopol ${ }^{\circledR} \quad$ (D $\quad \& \quad$ F $\quad$ Control Systems, Dublin, USA). Procedeu-se o acondicionamento em condições de refrigeração a fim de transportar para o Laboratório de Qualidade do Leite (LQL) da EV/UFG para a realização da Contagem de Células Somáticas CCS e determinação da composição do leite.

Em função dos resultados apresentados para a CCS, do volume de leite produzido e dos teores de proteína total e gordura, as vacas foram distribuídas em grupos para se obter leite com baixa CCS - nível 1 ( $\leq 200$ mil céls./mL), com nível médio - nível 2 (>200 a $\leq 400 \mathrm{mil}$ céls./mL), intermediário - nível 3 (>400 mil céls. $/ \mathrm{mL}$ a $\leq 750$ mil céls. $/ \mathrm{mL}$ ) e alto - nível 4 (>CCS 750 mil céls./mL).

$\mathrm{O}$ leite necessário à realização do experimento foi obtido por ordenha individual dos animais, três dias após as análises laboratoriais, e cada grupo foi ordenhado separadamente. O leite de cada grupo foi colhido na ordenha da manhã, em galões de polipropileno higienizados, com capacidade para 50 litros, os quais foram acondicionados em câmara fria a $5^{\circ} \mathrm{C}$ até o momento de sua utilização. Os queijos foram elaborados conforme as recomendações de Furtado (2005).

Foram colhidas assepticamente amostras de leite cru dos galões, destinados à realização das análises microbiológicas por meio da contagem bacteriana total (CBT) e físico-químicas por meio da realização da CCS, gordura, proteína, lactose, sólidos totais e ureia (BRASIL, 2003ab).

Após pasteurização do leite, foram colhidas amostras para a determinação do número mais provável (NMP) de coliforme a $35^{\circ} \mathrm{C}$ e $45^{\circ} \mathrm{C}$ (BRASIL, 2003a) e do perfil enzimático por meio da pesquisa das enzimas fosfatase alcalina e peroxidase (BRASIL, 2003b). Realizou-se também a amostragem do produto final por meio da colheita de três amostras por lote, 24 horas após a fabricação, nos $15^{\circ}$ e $30^{\circ}$ dias de armazenamento, dos queijos. Foram realizadas as seguintes análises: determinação do índice de proteólise (BYNUM \& BARBANO, 1985) e contagem de coliformes totais e fecais (BRASIL 2003a), dos microrganismos psicrotróficos aeróbios facultativos viáveis e bactérias ácido láctica (APHA, 2001). A proteólise foi quantificada por meio da determinação do nitrogênio solúvel em tampão acetato a $\mathrm{pH}$ 4,6 e em $12 \%$ de ácido tricloroacético (TCA) e os resultados expressos como percentagem do nitrogênio total.

O nitrogênio solúvel, em solução tampão de acetato a pH 4,6, quantifica a extensão da proteólise, como medida da ação do coagulante numa fase inicial do fracionamento dos componentes nitrogenados do queijo, enquanto $\mathrm{O}$ nitrogênio solúvel em $12 \%$ TCA quantifica a profundidade e mensura a atividade das enzimas provenientes da cultura láctica. O Nitrogênio Total (NT) foi determinado pelo método de Kjeldahl, conforme metodologia da AOAC (1995) 991.20 e a proteína total (PT) calculada pela multiplicação da porcentagem de NT por 6,38. Estes índices foram determinados no $1^{\circ}, 15^{\circ} \mathrm{e}$ 
Rev. Bras. Saúde Prod. Anim., Salvador, v.13, n.3, p.682-693 jul./set., 2012 http://www.rbspa.ufba.br ISSN 15199940

$30^{\circ}$ dias de maturação do queijo Mussarela.

Foi utilizado o delineamento experimental em blocos completamente aleatorizados. Os níveis de células somáticas foram considerados como parcela principal, enquanto o tempo de armazenamento e as respectivas interações como sub-parcelas. $\mathrm{Na}$ análise estatística, utilizou-se a análise de variância seguida do teste de Tukey, considerando $\mathrm{p}<0,05$ como probabilidade mínima aceitável para diferença entre as médias. O experimento completo foi repetido quatro vezes, com um intervalo de 70 dias entre cada repetição. Os resultados de CCS e das análises microbiológicas foram transformados em logaritmo natural, pois não possuem distribuição normal. A análise foi realizada com o auxílio Software livre $\mathrm{R}, 2.4 .1$.

\section{RESULTADOS E DISCUSSÃO}

Em relação à composição do leite, observa-se que ocorreu redução significativa nos teores de proteína com o aumento da CCS, acompanhado do aumento de ureia e gordura, entre o nível 4 e os demais níveis de CCS (Tabela 1). Em relação aos outros parâmetros analisados não houve diferença significativa entre os níveis avaliados.

Tabela 1. Indicadores da qualidade do leite associados a diferentes níveis de células somáticas. Goiânia, GO

\begin{tabular}{lllll}
\hline \multirow{2}{*}{ Parâmetros avaliados } & \multicolumn{4}{c}{ Níveis de CCS } \\
\cline { 2 - 5 } & Nível 1 & Nível 2 & Nível 3 & Nível 4 \\
\hline CCS (Log cél/mL)1 & $4,94 \pm 0,18$ & $5,46 \pm 0,10$ & $5,74 \pm 0,11$ & $6,27 \pm 0,12$ \\
CBT (log UFC/mL)2 & $5,10 \pm 0,41^{\mathrm{a}}$ & $4,93 \pm 2,13^{\mathrm{a}}$ & $5,35 \pm 0,44^{\mathrm{a}}$ & $5,19 \pm 0,36^{\mathrm{a}}$ \\
Proteína (\%) & $3,16 \pm 0,03^{\mathrm{a}}$ & $3,38 \pm 0,03^{\mathrm{a}}$ & $3,17 \pm 0,06^{\mathrm{a}}$ & $2,42 \pm 0,04^{\mathrm{b}}$ \\
Gordura (\%) & $3,10 \pm 0,20^{\mathrm{a}}$ & $3,14 \pm 0,19^{\mathrm{a}}$ & $3,00 \pm 0,11^{\mathrm{a}}$ & $3,51 \pm 0,36^{\mathrm{b}}$ \\
Lactose $(\%)^{\text {Sólidos totais }(\%)}$ & $4,53 \pm 0,09^{\mathrm{a}}$ & $4,43 \pm 0,13^{\mathrm{a}}$ & $4,40 \pm 0,08^{\mathrm{a}}$ & $4,36 \pm 0,09^{\mathrm{a}}$ \\
Ureia (mg/dL) & $11,62 \pm 0,37^{\mathrm{a}}$ & $12,42 \pm 1,18^{\mathrm{a}}$ & $11,91 \pm 0,54^{\mathrm{a}}$ & $11,78 \pm 0,31^{\mathrm{a}}$ \\
\hline
\end{tabular}

${ }^{\mathrm{T}}$ Contagem de células somáticas; ${ }^{2}$ Contagem bacteriana total; Valores com mesma letra na linha não diferiram significativamente entre si $(\mathrm{p} \leq 0,05)$.

Nível 1: leite com CCS baixa ( $\leq 200.000$ céls. $/ \mathrm{mL}$ ); Nível 2Leite com CCS média (>200 000 céls. $/ \mathrm{mL}$ $\leq 400.000$ céls./mL); Nível 3: leite com CCS intermediária (>400 000 céls. $/ \mathrm{mL} \leq 750.000$ céls. $/ \mathrm{mL}$ );

Nível 4: leite com CCS alta (>750 000 cél $/ \mathrm{mL})$;

Em vacas com mastite, observou-se lesão do epitélio glandular, o que pode levar a uma diminuição dos componentes sintetizados no interior da glândula, especialmente, a caseína, o que explica a diminuição no percentual de proteína do leite com alta CCS (OLIVEIRA et al., 2010; LANGONI et al., 2011). Em relação à gordura também se observou a diminuição da síntese (SOUZA et al., 2010), no entanto, quando a diminuição da produção ocorre de maneira mais drástica que a síntese, o teor de gordura sofre um aumento proporcional, o que pode ter ocorrido no presente estudo. No que diz respeito à ureia, sabe-se que o aumento da CCS relaciona-se a uma 
maior síntese de plasmina e do seu precursor inativo plasminogênio, enzima que hidrolisa as proteínas do leite em pequenas moléculas de peptídeos e ureia. Soma-se a isso, a capacidade de produção de substâncias ativadoras do plasminogênio pelos leucócitos (O’BRIEN et al., 2001).

Ao observar os teores médios de lactose e sólidos totais nos diferentes níveis CCS (Tabela 1) constata-se que não houve variação. Esses resultados estão em discordância com os obtidos por Souza et al. (2010) e Bueno et al. (2005) que mencionaram a ocorrência de redução desses parâmetros conforme o aumento da CCS.

Quanto à CBT, observa-se que não houve diferença significativa entre os diferentes níveis de CCS. Santos \& Fonseca (2007) relataram que geralmente o aumento na CCS não tem relação direta com a CBT, exceto nas infecções, nas quais o agente etiológico da mastite seja o Streptococcus agalactiae ou o S. dysgalactiae. No entanto, Rysanec et al. (2007), por meio da avaliação de CCS e CBT de 298 rebanhos, estabeleceram que valores superiores a 400 mil céls./mL correlacionam-se com a qualidade higiênico-sanitária, ou seja, com a CBT. Os autores encontraram uma correlação de 0,63 entre a CCS e a CBT. No que concerne à pasteurização, observa-se que o leite dos grupos apresentou-se em acordo com o preconizado pela legislação vigente, ou seja, a IN 62 do MAPA (Tabela 2).

Tabela 2. Análise de coliforme a $35^{\circ} \mathrm{C}, 45^{\circ} \mathrm{C}$ e enzimas do leite pasteurizado de acordo com diferentes níveis de contagem de células somáticas, Goiânia. GO

\begin{tabular}{|c|c|c|c|c|}
\hline \multirow{2}{*}{ Parâmetros } & \multicolumn{4}{|c|}{ CCS obtida nas repetições } \\
\hline & Nível 1 & Nível 2 & Nível 3 & Nível 4 \\
\hline $\begin{array}{l}\text { NMP1 de coliforme } 35^{\circ} \mathrm{C} \\
\text { (LogNMP/mL) }\end{array}$ & $<0,3$ & $<0,3$ & $<0,3$ & $<0,3$ \\
\hline NMP de coliforme $45^{\circ} \mathrm{C}(\operatorname{LogNMP} / \mathrm{mL})$ & $<0,3$ & $<0,3$ & $<0,3$ & $<0,3$ \\
\hline Pesquisa de Fosfatase alcalina & Negativo & Negativo & Negativo & Negativo \\
\hline Pesquisa de Peroxidase & Positivo & Positivo & Positivo & Positivo \\
\hline
\end{tabular}

Ao contrastar os resultados das análises realizadas no leite pasteurizado e os padrões previstos na Instrução Normativa $\mathrm{N}^{\circ} 62$, no regulamento técnico e de identidade e qualidade, observa-se que aqueles estão em acordo com a legislação vigente (BRASIL, 2011). As IN51 e a IN62 preconizam para a análise de coliforme $35^{\circ} \mathrm{C}$ um resultado $2,0 \mathrm{NMP} / \mathrm{mL}$ e para o coliforme $45^{\circ} \mathrm{C}$ $<0,3 \mathrm{NMP} / \mathrm{mL}$ (BRASIL, 2011).
Salienta-se, que se o tratamento térmico for realizado de forma adequada, sem deixar de respeitar o binômio tempo/temperatura recomendados, ocorrerão à destruição dos patógenos e de grande parte dos micro-organismos termolábeis, entre os quais, os coliformes. Em relação ao perfil enzimático, ao se considerar que o leite foi submetido ao processo de pasteurização lenta, os resultados já eram esperados, ou seja negativo para fosfatase alcalina, e 
Rev. Bras. Saúde Prod. Anim., Salvador, v.13, n.3, p.682-693 jul./set., 2012 http://www.rbspa.ufba.br ISSN 15199940

positivo para peroxidase (BRASIL, 2002; BRASIL, 2011).

No que se refere aos aspectos microbiológicos dos queijos, apenas a contagem de bactérias ácido lácticas sofreu influência dos parâmetros CCS e tempo de armazenamento (Tabela 3). A contagem de micro-organismos psicrotróficos foi influenciada apenas pelo tempo de armazenamento.

Tabela 3. Médias de coliformes $35^{\circ} \mathrm{C}, 45^{\circ} \mathrm{C}$, psicrotróficos e bactérias ácido lácticas em queijo Mussarela, elaborado com leite composto de diferentes níveis de células somáticas, nos dias um, $15^{\circ}$ e $30^{\circ}$ de armazenamento a $7^{\circ} \mathrm{C}$

\begin{tabular}{|c|c|c|c|c|c|}
\hline Grupos & DIA 1 & DIA 15 & DIA 30 & \multirow{2}{*}{$\mathrm{CV}(\%)$} & \multirow{2}{*}{ Regressão } \\
\hline \multicolumn{4}{|c|}{ Contagem de coliformes $35^{\circ} \mathrm{C}$ ( $\mathrm{Log} \mathrm{UFC} / \mathrm{g}$ ) } & & \\
\hline Nível 1 & $1,00 \pm 0,00$ & $1,00 \pm 0,00$ & $1,00 \pm 0,00$ & \multirow{4}{*}{0,00} & \multirow{4}{*}{ NS } \\
\hline Nível 2 & $1,00 \pm 0,00$ & $1,00 \pm 0,00$ & $1,00 \pm 0,00$ & & \\
\hline Nível 3 & $1,00 \pm 0,00$ & $1,00 \pm 0,00$ & $1,00 \pm 0,00$ & & \\
\hline Nível 4 & $1,00 \pm 0,00$ & $1,00 \pm 0,00$ & $1,00 \pm 0,00$ & & \\
\hline \multicolumn{4}{|c|}{ Contagem de coliformes $45^{\circ} \mathrm{C}(\mathrm{Log} \mathrm{UFC} / \mathrm{g})$} & & \\
\hline Nível 1 & $1,00 \pm 0,00$ & $1,00 \pm 0,00$ & $1,00 \pm 0,00$ & \multirow{4}{*}{0,00} & \multirow{4}{*}{ NS } \\
\hline Nível 2 & $1,00 \pm 0,00$ & $1,00 \pm 0,00$ & $1,00 \pm 0,00$ & & \\
\hline Nível 3 & $1,00 \pm 0,00$ & $1,00 \pm 0,00$ & $1,00 \pm 0,00$ & & \\
\hline Nível 4 & $1,00 \pm 0,00$ & $1,00 \pm 0,00$ & $1,00 \pm 0,00$ & & \\
\hline \multicolumn{4}{|c|}{ Contagem de bactérias ácido lácticas (Log UFC/g) } & & \\
\hline Nível 1 & $6,72 \pm 0,82^{\mathrm{aA}}$ & $6,85 \pm 0,12^{\mathrm{aA}}$ & $7,01 \pm 0,29^{\mathrm{aA}}$ & \multirow{4}{*}{10,89} & \multirow{4}{*}{$\begin{array}{l}\text { Efeito } \\
\text { Linear* }\end{array}$} \\
\hline Nível 2 & $6,41 \pm 0,70^{\mathrm{aA}}$ & $6,76 \pm 0,90^{\mathrm{aA}}$ & $6,81 \pm 0,72^{\mathrm{aA}}$ & & \\
\hline Nível 3 & $6,98 \pm 0,20^{\mathrm{aA}}$ & $6,84 \pm 0,87^{\mathrm{aA}}$ & $6,89 \pm 0,58^{\mathrm{aA}}$ & & \\
\hline Nível 4 & $5,86 \pm 0,32^{\mathrm{aB}}$ & $4,76 \pm 0,60^{\mathrm{aB}}$ & $4,87 \pm 0,83^{\mathrm{aB}}$ & & \\
\hline \multicolumn{4}{|c|}{ Contagem de psicrotróficos (Log UFC/g) } & & \\
\hline Nível 1 & $1,00 \pm 0,00^{\mathrm{aA}}$ & $2,74 \pm 0,52^{\mathrm{aB}}$ & $2,95 \pm 0,34^{\mathrm{aC}}$ & \multirow{4}{*}{28,25} & \multirow{4}{*}{$\begin{array}{c}\text { Efeito } \\
\text { Linear** }\end{array}$} \\
\hline Nível 2 & $1,00 \pm 0,00^{\mathrm{aA}}$ & $2,75 \pm 0,26^{\mathrm{aB}}$ & $3,01 \pm 0,09^{\mathrm{aC}}$ & & \\
\hline Nível 3 & $1,00 \pm 0,00^{\mathrm{aA}}$ & $2,83 \pm 0,70^{\mathrm{aB}}$ & $3,18 \pm 0,11^{\mathrm{aC}}$ & & \\
\hline Nível 4 & $1,00 \pm 0,00^{\mathrm{aA}}$ & $2,77 \pm 0,61^{\mathrm{aB}}$ & $3,18 \pm 0,90^{\mathrm{aC}}$ & & \\
\hline
\end{tabular}

Nível 1: leite com CCS baixa ( $\leq 200.000$ céls./mL); Nível 2: leite com CCS média (>200 000 céls./mL $\leq 400.000$ céls. $/ \mathrm{mL}$ ); Nível 3: leite com CCS intermediária ( $>400000$ céls. $/ \mathrm{mL} \leq 750.000$ céls. $/ \mathrm{mL}$ ); Nível 4: leite com CCS alta (>750 000 céls. $/ \mathrm{mL}$ ); NS: não significativo para $\mathrm{p} \leq 0,05$ pela Análise de Variância. *Efeito linear para o nível de CCS e tempo. ** Efeito linear para o tempo.

Quanto à contagem de coliformes a $35^{\circ} \mathrm{C}$ e $45^{\circ} \mathrm{C}$, os resultados contidos na Tabela 4 apresentam-se em acordo com os padrões previsto na Portaria $\mathrm{n}^{\circ} 146$ (BRASIL, 1996), o que comprova que a produção foi realizada de acordo com os requisitos de Boas Práticas de Fabricação (BPF) e Procedimento Padrão de Higiene Operacional (PPHO). 
Em geral, os valores das contagens de bactérias ácido lácticas apresentaram ligeiro aumento, durante o período de estocagem, de modo a indicar a multiplicação dessa microbiota presente nos queijos. Porém, no produto elaborado com CCS superior a 750 mil céls./mL, observa-se ligeira diminuição (Figura 1).

Aproximadamente $67 \%(\mathrm{R} 2=0,67)$ dos fatores relacionados à inibição da cultura iniciadora ou das bactérias ácido lácticas, utilizadas no processo de coagulação do queijo Mussarela, produzido com CCS superior a $750 \mathrm{mil}$ céls/mL, foi associado ao aumento do parâmetro (Figura 1). Isso pode ser explicado em parte, pela injúria sofrida pelos micro-organismos devido à ação de enzimas antimicrobianas provenientes de leite com alta CCS (LE ROUX et al., 2003; MAZAL et al., 2007).

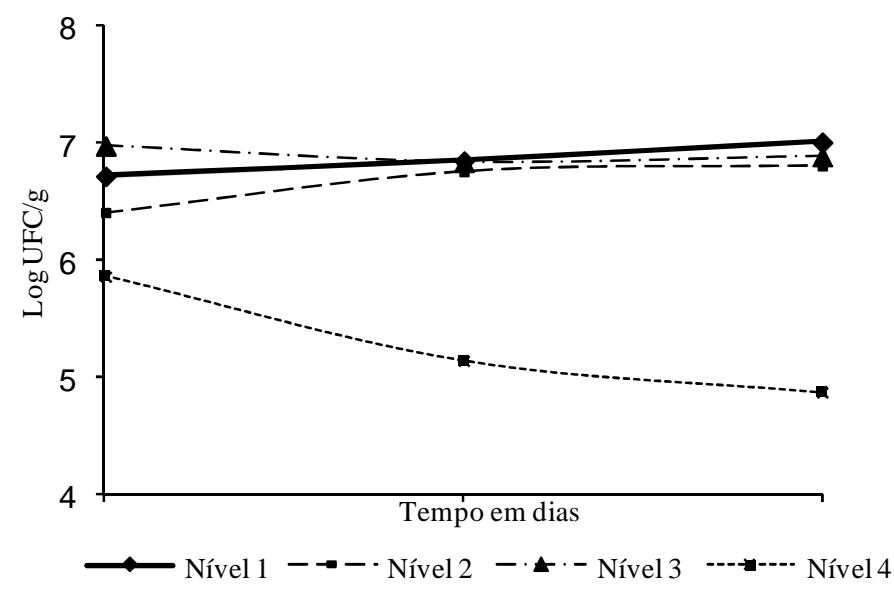

Figura 1. Efeito dos níveis de células somáticas sobre as bactérias ácido lácticas do queijo Mussarela nos dias um, $15^{\circ}$ e $30^{\circ}$ de armazenamento a $7^{\circ} \mathrm{C}$

No entanto, nota-se que os índices ou contagens de micro-organismos psicrotróficos não foram superiores a 3,18log UFC/g (Figura 2). Nessas condições, não ocorre produção de enzimas proteolíticas e lipolíticas (PARK, 2001; SANTOS \& FONSECA, 2007) em quantidades suficientes para causar danos às características físico-químicas e sensoriais dos queijos (PARK, 2001). Essas informações são importantes para explicar o que ocorreu no presente trabalho, pois no primeiro dia de análise não foi observada a presença desse tipo de micro-organismo nos queijos, mas a partir do $15^{\circ}$ dia ocorreu o aumento gradativo até $30^{\circ}$ dia de armazenamento ou maturação a $7^{\circ} \mathrm{C}$, como visualizado na Tabela 3. O interessante é que foi observada uma influência de $99 \%(\mathrm{R} 2=0,99)$ entre o processo de armazenamento e o crescimento dos micro-organismos psicrotróficos. A evolução dos índices de extensão da maturação (IEM) e de profundidade da maturação (IPM) da proteólise dos queijos foi superior para os queijos produzidos com CCS superior a 400mil céls/mL (Figuras 2 e 3 ). 


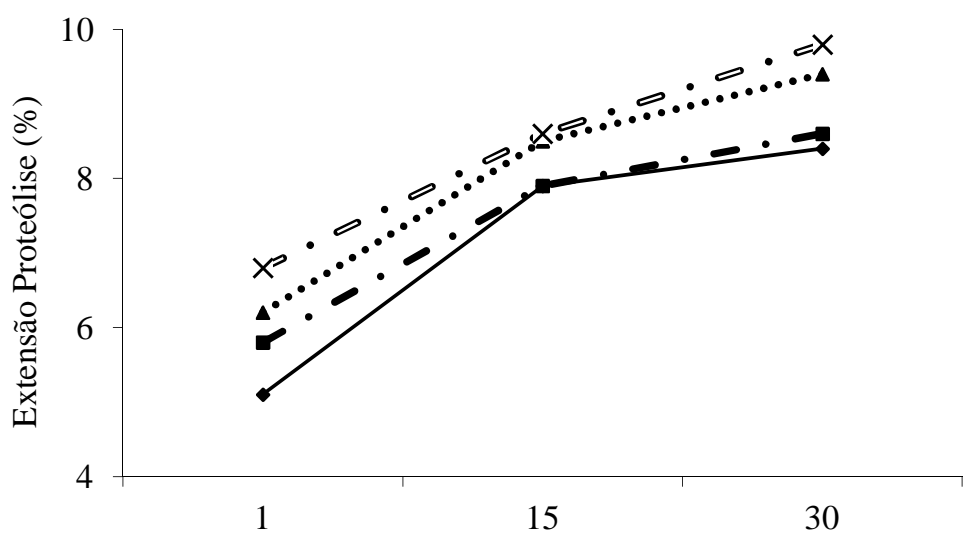

Figura $\overrightarrow{2 \text {. Índices de }}$ dével 1 extensão da proteólise dos queijos fabricados com leite composto de diferentes níveis de células somáticas (1-CCS $\leq 200$ mil céls./mL; 2-CCS $>400$ a $\leq 400$ mil céls. $/ \mathrm{mL}$; 3-CCS >400 mil céls./mL a $\leq 750$ mil céls. $/ \mathrm{mL}$ e 4 -CCS $>750$ mil céls. $/ \mathrm{mL}$ ) durante o período de armazenamento a $7^{\circ} \mathrm{C}$.

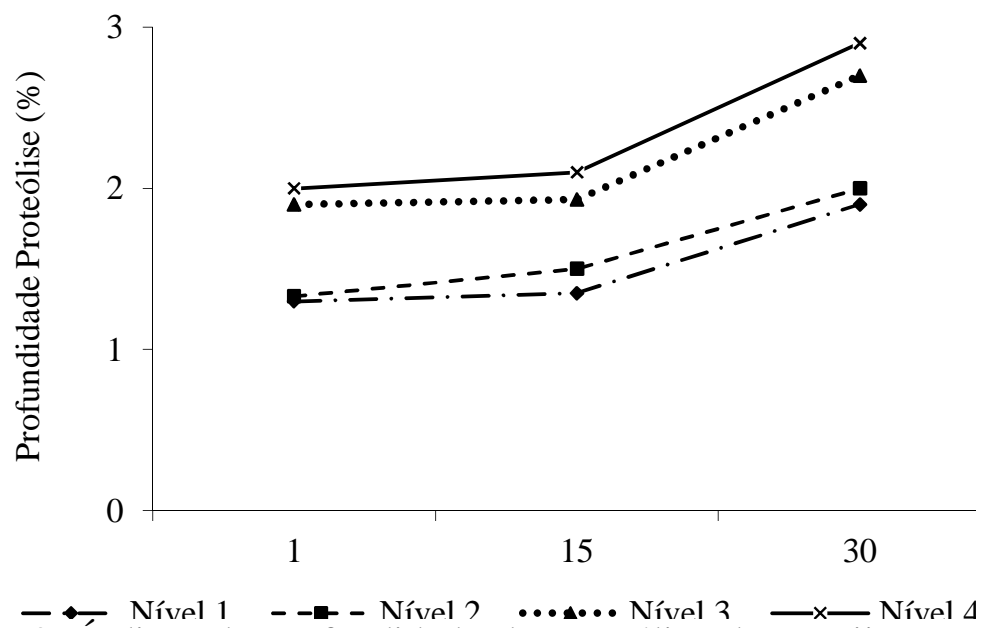

Figura $\overline{3}$. Índices de profundidade da proteólise dos queijos fabricados com leite composto de diferentes níveis de células somáticas (1- $\leq 200$ mil céls./mL; 2-CCS $>400$ a $\leq 400$ mil céls. $/ \mathrm{mL}$; 3-CCS $>400$ mil céls. $/ \mathrm{mL}$ a $\leq 750$ mil céls. $/ \mathrm{mL}$ e 4-CCS $>750 \mathrm{mil}$ céls. $/ \mathrm{mL}$ ) durante o período de armazenamento a $7^{\circ} \mathrm{C}$.

O tempo de armazenamento afetou significativamente os índices de extensão da maturação e de profundidade da maturação da proteólise, os quais aumentaram ao longo dos dias. Convém destacar que houve diferença significativa para os queijos elaborados com CCS superior a 400 mil céls./mL 
(Figuras 2 e 3). Segundo Fox \& Law (1991), a maturação é caracterizada pela quebra das proteínas presentes no queijo, especialmente, as caseínas, como resultado da atividade enzimática. Contribuem para esse processo o coalho, proteases e peptidases do fermento lático e/ou microbiota secundária e enzimas naturais do leite. Os autores ressaltam ainda que durante a proteólise ocorre fragilização da rede proteica do queijo, o que aumenta a capacidade de derretimento do mesmo. Tal propriedade é importante para o queijo Mussarela, uma vez que a aceitabilidade do produto pelo consumidor está relacionada com essa característica.

A relação entre a utilização do leite com alto nível de CCS e o grau de proteólise em queijos tem sido motivo de estudo em todo mundo (KALIT et al., 2005; MARINO et al., 2005; ANDREATTA et al., 2006). No entanto, observa-se que os resultados são contraditórios. Kalit et al. (2005), por exemplo, não constataram efeito do nível de CCS sobre a proteólise do queijo elaborado com leite formado por CCS superior a 500 mil céls. $/ \mathrm{mL}$.

Resultados similares aos encontrados no presente estudo, foram obtidos por Cooney et al. (2000) e Marino et al. (2005) os quais afirmaram que a proteólise aumentou ao longo do tempo de armazenamento e foi sempre maior para os queijos fabricados com leite constituído de alta CCS. Por outro lado, Andreatta et al. (2006) observaram que houve diminuição da proteólise em amostra de queijo minas frescal, elaborado com leite composto de CCS >800 mil céls./mL. Os autores justificaram a diminuição com o aumento das substâncias antimicrobianas que ocorre no leite com alta CCS. Ainda, segundo os autores, a cultura láctea não se desenvolve adequadamente, o que inibe, consequentemente, o grau de proteólise durante o período de armazenamento.
Destaca-se que no presente estudo também foi observada a inibição dos micro-organismos utilizados na cultura láctea (nível 4), contudo deve-se levar em consideração que no leite mastítico ocorre maior produção de proteases não bacterianas, que pode ter se sobreposto a esse processo de inibição enzimática de origem microbiana.

No leite mastítico, observa-se o aumento de enzimas proteolíticas, especialmente, a plasmina e seu precursor inativo $\mathrm{o}$ plasminogênio. Além dessas, outras enzimas originadas das células somáticas e dos leucócitos contribuem para a atividade proteolítica no leite. Nesse sentido, Considine et al. (2004) estudaram a Catepsina-G que é uma das principais proteases liberadas pelos polimorfonucleares. Os autores verificaram a capacidade da enzima de hidrolisar as $\alpha$ s1 e $\beta$-caseínas, com produção de peptídeos similares aos liberados pela plasmina, e concluíram que a catepsina-G pode contribuir de maneira significativa para a proteólise que ocorre no leite com alta CCS.

Verdi \& Barbano (1991) observaram no leite com alta CCS a presença de produtos de hidrólise de caseínas, diferentes daqueles produzidos pela plasmina, após sua inativação. Segundo os autores, as proteases envolvidas nessa hidrólise foram fornecidas pelos macrófagos, que apresentaram maior atividade no leite do que no sangue. Assim, observa-se que a atividade proteolítica no leite com alta CCS é particularmente estável. Deve-se ressaltar que a pasteurização do leite com alta CCS não elimina totalmente a atividade proteolítica originária das células somáticas, e que, essa atividade permanece mesmo quando a CCS do leite retorna a um nível baixo, após $\mathrm{o}$ tratamento da infecção (MARINO et al., 2005). 
Conforme exposto, a alteração no leite mastítico poderá cursar com aumento da proteólise e inibição da cultura láctea utilizada na elaboração do queijo Mussarela. Ao considerar os resultados obtidos e as condições de realização do presente experimento, conclui-se que a elevação da CCS está relacionada à diminuição das bactérias ácido lácticas e ao aumento da extensão e da profundidade da proteólise do queijo, durante o período de maturação ou armazenamento a $7^{\circ} \mathrm{C}$.

\section{REFERÊNCIAS}

ALBENZIO, M.; CAROPRESE, A.; SANTILLO, M.; MARINO, L.; TAIBI, R.; SEVI A. Effects of somatic cell Count and Stage of Lactation on the Plasmina Activity and Cheese-Making Properties of Ewe milk. Journal of Dairy Science, v.87, p.533-542, 2004.

AMERICAN PUBLIC HEALTH ASSOCIATION - APHA.

Compendium of methods for the microbiological examination of foods. 4.ed. Washington, 2001.

ANDREATTA, E; OLIVEIRA, C.A.F.; MARQUES, C.M.; FERNANDES, A.M.; SANTOS, M.V. Avaliação do rendimento e proteólise do Queijo Minas Frescal produzido com diferentes níveis de células somáticas: resultados preliminares. Brazilian journal of food Technology, n.12, p.71-74, 2006.

ASSOCIATION OF OFFICIAL ANALYTICAL CHEMISTS.- AOAC. Official methods of analysis of AOAC international. 16.ed. Washington, 1995. v.1-2.
BRASIL. Instrução Normativa Número 51 de 18 de setembro de 2002. Dispõe sobre regulamentos técnicos aplicados ao leite cru e pasteurizado. Diário Oficial da União, Brasília, set. 2002. Seção 1, n.83, p.13-22, 20.

BRASIL. Instrução Normativa Número 62 de 29 de setembro de 2011. Dispõe sobre regulamento técnico de produção, identidade e qualidade do leite tipo A, do leite cru refrigerado, do leite pasteurizado e o regulamento técnico da coleta de leite cru Refrigerado e seu Transporte a Granel. Diário Oficial da União, Brasília, 20 set. 2011.

BRASIL. Portaria ${ }^{\circ} 146$ de 07 de março de 1996. Regulamentos técnicos de identidade e qualidade de produtos lácteos. Diário Oficial da União, Brasília, 11 mar.1996. BRASIL. Instrução Normativa ${ }^{\circ}$ 62, de 26 de agosto de 2003. Métodos analíticos oficiais para análises microbiológicas para controle de produtos de origem animal e água. Diário Oficial da União, Brasília, 18 set. 2003a. Seção 1, p.14-51.

BRASIL.. Instrução Normativa $n^{0} 22$, de 02 de maio de 2003. Métodos analíticos oficiais físico-químicos, para controle de leite e produtos lácteos. Diário Oficial da União, Brasília, 14 abr. 2003b. Seção 1, p.1-110,

BUENO, V.F.F.; MESQUITA, A.J.; NICOLAU, E.S.; OLIVEIRA, A.N.; OLIVEIRA, J.P.; NEVES, R.; BALDUÍNO S; MANSUR, J.R.G.; THOMAZ, L.W. Contagem celular somática: relação com a composição centesimal e estação do ano no Estado de Goiás. Ciência Rural, v.35, n.4, p.848-854, 2005. 
Rev. Bras. Saúde Prod. Anim., Salvador, v.13, n.3, p.682-693 jul./set., 2012 http://www.rbspa.ufba.br ISSN 15199940

BYNUM, D.G.; BARBANO, D.M.

Whole milk reverse osmosis retentates for cheddar cheese manufacturing: chemical changes during ageing. Journal of Dairy Science, v.68, n.1, p.1-10, 1985.

CONSIDINE, T.; KELLY, A.L.; HEALY, A.; McSWEENEY, P.L.H. Hydrolysis of bovine caseins by cathepsin $\mathrm{B}$, a cysteine protease indigenous to milk. International Dairy Journal, v.14, n.117-124, 2004.

COONEY, S.; TIERNAN, D.; JOYCE, P.; KELLY, A.L. Effect of somatic cell count and polymorphonuclear leucocyte content of milk on composition and proteolysis during ripening of Swiss-typecheese. Journal of Dairy Research, v.67, n.2, p.301-307, 2000.

FOX, P.F.; LAW, J. Enzimology of cheese ripening. Food Biotechnology, v.54, n.10, p.801-809, 1991.

FURTADO, M.M. Principais problemas dos queijos: causas e prevenção. 2. ed. São Paulo: Fonte Comunicações e Editora, 2005. 200 p.

KALIT, S.; HAVRANEK, L.J.; KAPS, M.; PERKO, B.; CUBRIC, C.V.

Proteolysis and the optimal ripening time of Tounj cheese. International Dairy Journal, v.15, n.6-9, p.619-624, 2005.

KELLY, A.L.; MCSWEENEY, P.L.H. Indigenous proteinases in milk.

Advanced Dairy Chemistry, v.1, p.494519, 2002.

LANGONI H.; SAKIYAMA, D.T.P.; GUIMARÃES, F.F; CAMOSSI, L.G.; SILVA, A.V. Contagem de células somáticas e de microrganismos mesófilos aeróbios em leite cru orgânico produzido em Botucatu (SP). Veterinária e Zootecnia, v.18, n.4, p.653-660, 2011.
LE ROUX, Y.; LAURENT, F.; MOUSSAOUI, F. Polymorphonuclear proteolytic activity and milk composition change. Veterinary Research, v.34, n.5, p.629-645, 2003.

MARINO, R.; CONSIDINE, T.; SEVI, A.; MCSWEENEY, P.L.H.; KELLY, A.L Contribution of proteolytic activity associated with somatic cells in milk to cheese ripening. International Dairy Jornal, v.11, n.1, p.11-27, 2005.

MAZAL, G.; VIANNA, P.C.B.; SANTOS, M.V.; GIGANTE, M.L. Effect of somatic cell count on prato cheese composition. Journal of Dairy Science, v.90, p.630-636, 2007.

O'BRIEN, B.; MEANEY, W.J.; MCDONAGH, D.; KELLY, A. Influence of somatic cell count and storage interval on composition and processing characteristics of milk from cows in late lactation. Australian Journal Dairy Technology, v.56, p.213-218, 2001.

OLIVEIRA, U.V.; GALVÃO, G.S.; PAIXÃO, A.R.R.; MUNHOZ, A.D. Ocorrência, etiologia infecciosa e fatores de risco associados à mastite bovina na microrregião Itabuna-Ilhéus, Bahia. Revista Brasileira Saúde Produção Animal [Online], v.11, n.3, p.630-640, 2010.

PARK, Y. Proteolysis and lipolysis of goat milk cheese. Journal of Dairy Science, v.84, p.84-92, 2001.

REVILLA, I.; RODRIGUES, J.M.; QUINTANA, A.M.V. Proteolysis and texture of hard ewes' milk cheese during ripening as affected by somatic cell counts. Journal of Dairy Research, v.74, n.2, p.127-36, 2007. 
RYSANEK, D.; BABAK, V.;

ZOUHAROVA, M. Bulk tank milk somatic cell count and sources of raw. milk contamination with mastitis pathogens. Veterinarian Medicina, v.52, n.6, p.223-230, 2007.

SANTOS, M.V.; CAPLANZ, M.Y.; BARBANO, D.M. Effect of somatic cell count on proteolysis and lipolysis in pasteurized fluid milk during shelf-Life Storage. Journal of Dairy Science, v.90, n.8, p.2491-2503, 2003a.

SANTOS, M.V.; CAPLANZ, M.Y.; BARBANO, D.M. Sensory Threshold of Off-Flavors Caused by Proteolysis and Lipolysis in Milk. Journal of Dairy Science, v.86, p.1601-1607, 2003b.
SANTOS, M.V.; FONSECA, L.F.L.

Estratégias para o controle da mastite e melhoria da qualidade do leite. Barueri, SP: Manole. 2007. 314p.SOUZA, R.; SANTOS, G.T.; VALLOTO, A. A. SANTOS, A.L.; GASPARINO, E.; SILVA, D.C.; SANTOS, W. B. R. Produção e qualidade do leite de vacas da raça Holandesa em função da estação do ano e ordem de parto. Revista

Brasileira de Saúde e Produção Animal [Online], v.11, n.2, p.484-495, 2010 .

VERDI, R.J.; BARBANO, D.M. Effect of coagulants, somatic cell enzymes, and extracellular bacterial enzymes on plasminogen activation. Journal of Dairy Science, v.74, n.3, p.772-782, 1991.

Data de recebimento: 14/02/2012

Data de aprovação: 22/08/2012 